\title{
Important issues for feminist nutrition research - a case study from the savanna of West Africa
}

\section{Gill Gordon}

Nutrition researchers tend to focus on the questions, 'Who is malnourished, when and where?' They examine dietary practices and epidemiology to understand better the immediate causes of malnutrition. They may record changes in these factors over time. Nutritionists are often less willing and able to research the underlying basic causes of malnutrition to do with social and economic factors and processes [Schofield 1979]. The distribution of resources and power determines nutrition at various levels. Malnutrition occurs most frequently in young females in the household; in poorer households in the community; in deprived regions of the nation; and in the poorest countries of the world. This article describes my experience over nine years working as a nutritionist in the savanna of West Africa. This learning process transformed me from a 'scientific' nutrition educator who expected mothers to follow narrow and alien ideas on feeding children, to a feminist mother convinced that mothers have a lot to teach if nutrionists would only stop lecturing and spend more time listening.

\section{Eat More Eggs and Oranges}

Equipped with a BSc Nutrition (London) and great enthusiasm, my career began with the Ministry of Health, Zaria, Northern Nigeria in 1966. Savanna children are at risk from the marasmic, 'skin and bones' type of malnutrition, particularly over the weaning period. My inherited tasks were to run a nutrition rehabilitation unit, to teach mothers at clinics, and to train local auxiliaries. These were the universal nutritional messages at this time:

- start to give supplementary foods at the age of three months;

- make a soft 'pap' with water and cereal flour;

- add mashed or pounded protein-rich foods to the pap, for example, egg;

- give young children plenty of vegetables, mashed fruits and juices, for example, orange juice.

We energetically spread these messages to as many mothers as possible using flannelgraphs, food groups and cooking demonstrations. The year passed with little feedback from our clients and no formal evaluation. In common with many nutrition educators, we did not know whether our activities were useful or not.

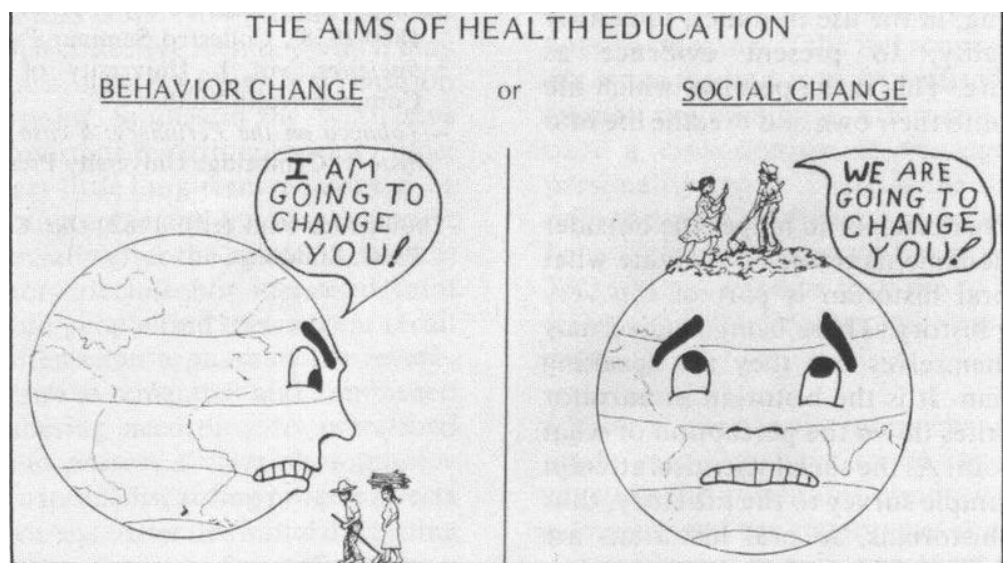

'Lasting changes will come from inside, from the people themselves', IIelping Health Workers Learn. David Werner and Bill Bower. The Hesperian Foundation. USA, 1982

IDS Bulletin. 1984, vol 15 no 1, Institute of Development Studies, Sussex 


\section{Nutrition Education - Blaming the Victim or Fighting Poverty?}

In 1969 I carried out an evaluation of nutrition education given to mothers at clinics in the Bawku district of the upper region of Ghana. The environment and the programme were similar to those I had been working with in Zaria. I designed a formal questionnaire to assess changes in knowledge, attitudes and dietary practices related to nutrition education, and to record data on social, economic and biological factors. I administered the questionnaire through a local sixth-form schoolboy to 301 mothers in 136 compounds. I weighed 498 children under five years of age, and measured their height, and head and arm circumferences. I lived in two high-income and two low-income households during three seasons: the dry post-harvest season, the rainy 'hungry' season, and the hot season when food was getting scarce. In these intensive studies I weighed food intakes and observed the daily routines of mothers and their young children. The two rich mothers and one of the poorer mothers had attended nutrition lessons, while the other poor mother had not had any contact with the programme. Mothers remembered the nutritional advice well. When they were asked what meals and snacks their young children ate yesterday, they reported that they ate the recommended foods. Observations, informal conversations and nutritional status measurements told a different story. Many mothers appeared to be trying to please the interviewer by reporting 'correct' feeding practices.

In the rainy farming season, the poor mother with nutrition education was out all day and prepared only one meal of millet flour and water, or boiled vegetables. The weanling child was carried on the mother's back and obtained most of her food by sucking on demand day and night. The older children shared insufficient food from one bowl. The mother said angrily, 'These nurses tell us to give our children more groundnuts and beans when we can't even give them millet.' The poor, 'ignorant' family impoverished themselves and delighted their children by buying rice, ground nut stew and fried beancakes from the market over the period of observation. They needed more resources, not nutritional information. The better-off mothers cooked the recommended foods, but they often failed to get them into their weaning children. Whenever they were sick, the children reverted to breastmilk only (on average, one day in three). They often slept before the evening meal was ready. As a result of all these problems, missed meals were a major cause of low food intakes.

Nutritional status measurements suggested that nutritional education was having a negative impact on nutrition. How could nutrition education make things worse? As suggested by other studies [eg Watkinson
1981] the costs of earlier supplementary feeding may outweigh the benefits in a poor; insanitary environment. Watery, contaminated paps will cause earlier diarrhoea and perhaps a fall in breastmilk production if children suck less. Pap is less nutritious than breastmilk even if an egg is added.

The local weaning food in Bawku is a soft millet dough, saab, with dark green slippery leaves and fermented locust beans, dawadawa. This is easy to swallow, tasty and given between the ages of seven and 12 months. It is more nutritious and safer than the pap and egg because it is fermented, preserved with ash salts, and contains less water and animal proteins. The local weaning practices probably worked better in this situation than imported, 'optimal' practices.

Many nutrition educators 'blame the victim' and aim to change the practices of individual mothers. Advice does not deal with real problems or match the resources and opportunities of the mother. This type of education increases guilt and anxiety but does not enable parents to change their situation. Nutrition education rarely involves dialogue and the information controlled by 'experts' changes every few years. As indicated above, in cases it may be dangerously inappropriate. Participatory research is needed to understand what prevents parents from feeding their children as they would like, and to find ways of creating a safe and healthy environment where good nutrition becomes possible. This may require action both at community and policy and planning level [Draper 1980]. An example: one cause of malnutrition is that children miss the evening meal because they sleep before it is ready. The standard recommended 'solution' is that mothers should wake the children up and feed them. However, the real problem is long working hours and laborious cooking methods. This raises a question for practical research: what can be done to lessen workloads and make cooking easier? When the real problem is identified, solutions are possible; for example: in Upper Volta grinding mills have enabled women to cook an extra meal in the farming season [McSweeney 1979].

My research in Bawku district showed that all the women in the sample breastfed their children on demand for at least 18 months. Even so, around 30 per cent of the children became malnourished over the weaning period. This situation is typical of many rural areas in the Third World. These mothers have to overrely on breastmilk because of poverty. They are reluctant to begin supplementary feeding because they have experienced the cycles of diarrhoea and wasting which often occur at this time. When they finally give foods late in the first year the children may reject them, and be less able to cope with pathogens because of undernutrition. Children are at high risk of malnutrition after weaning, whenever it occurs, because they are deprived of one of the high quality 
foods available. However, the continuing provision of this high quality food adds to women's exhaustion as they carry heavy children around with them all day and suckle them all night.

Rigid prescriptions on the timing of supplementation and the pattern of breastfeeding are not helpful to mothers faced with an insanitary environment and a shortage of time, fuel and cash. WHO, UNICEF and other international agencies vigorously promote the 'breast is best' message, assuming that women's work is compatible with breastfeeding, and that sucking missed in the day can be made up for at night. There is a danger that this great emphasis on breastfeeding will put the burden for survival on women, and divert attention from the need to improve sanitation and water supplies, income and domestic technology before women can wean more of their children successfully. Safe, local, cheap, convenient alternatives to a breastfeed would enable women to combine breastmilk and supplements in the best way to meet nutritional and work needs [Raphael 1979]. Research is needed on the effect of carrying heavy children and continuous demand feeding on women's health, nutrition and productivity. As has been recommended elsewhere, energy budgets of women over a year linked to fluctuations in body weight, birth weights and weight gain in infancy, and socioeconomic factors would be useful [FAO Food and Nutrition Paper 8, 1979].
On the basis of my evaluation of the effect of nutrition education in Bawku district I made the following recommendations [Gordon 1972]:

- an integrated health, agricultural and nutrition (HAN) programme supported by the relevant ministries is needed to achieve better nutrition;

- local men and women should be trained to teach nutrition in a more participatory way in the villages as well as the health units;

- the 'messages' should emphasise total food intakes and local practices, including frequent meals; greater use of fats and oilseeds; more soup; and supplements at 5-6 months with a cheaper local 'multimix'.

\section{Obstacles to Inter-ministerial Cooperation}

In 1972 the Bawku district health service set out to implement these recommendations, convinced of the necessity for increased cooperation between the public, extension and community workers and the heads of different sectors.

However, intersectoral cooperation is difficult when ministeries have different policy objectives which define the tasks of local workers. The Ghana Ministry of Agriculture has two branches:

- the agricultural section (staffed overwhelmingly by men) aims to extract the most surplus at the least

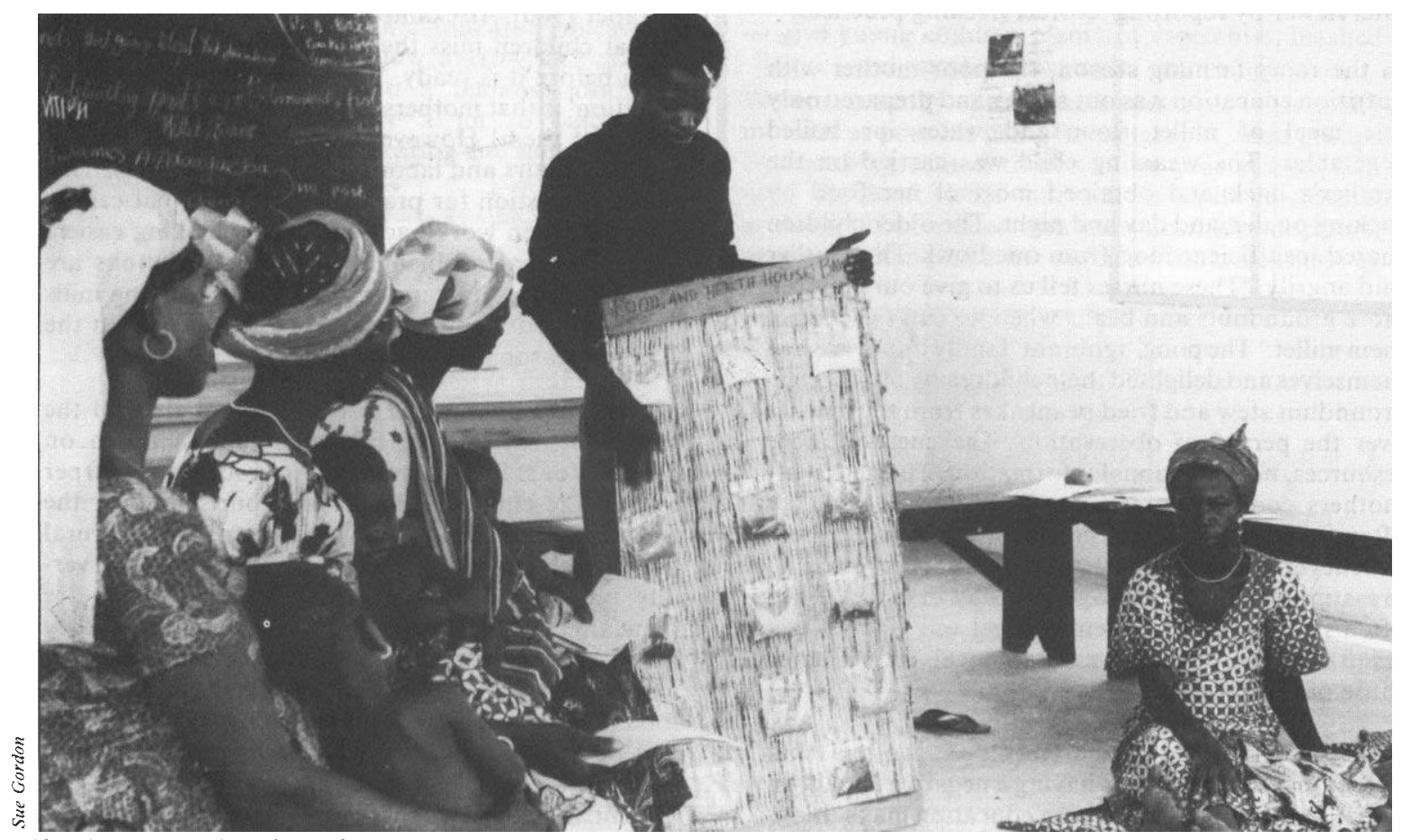

Nutrition demonstration. Ghana - does it mean anything to the audience? 
cost from rural producers. Extension workers supply inputs to better-off male farmers for cash crops. The ministry is reluctant to give credit for 'backyard' food crops in case the household's will to survive interferes with willingness to repay;

- the home economics section (all women) reaches women with information on domestic organisation, home gardens and small livestock keeping. A lack of resources often limits these workers to marginal activities.

The nutrition department of the Ministry of Health aims to increase the consumption of nutritious foods by influencing demand, by promoting food crops and sometimes by increasing incomes. It is seen as a welfare service for women and children, made up of cooks who fry fish for meetings and feed malnourished children. There was a single, and not very effective woman nutritionist in the Ministry of Economic Planning.

Research on the interactions between these sections at both the grassroots and national level might show how we can begin to change the policies which burden women with the family food supply and reproduction, and divert men to cash crops, investment, credit repayment and personal consumption. [Bukh 1977, Conti 1979, Whitehead 1981 \}. The economic activities of women have a major influence on nutritional status because women tend to use their personal income on extra food for their children [Tripp 1978]. Policy recommendations to improve nutrition now include ways to increase income for women. Many mothers with small children spend long hours working for low returns. The 'compatibility' of work with childcare may hide a far from optimal situation for mother and child. The child tied to the back for long periods is denied opportunities to develop motor and social skills. The mother strains her back, adds to her energy deficit, and limits her profits. Higher returns to labour and alternative ways of caring for children would enable mothers to work for shorter hours and children to learn. A more equal sharing of productive, domestic and reproductive work between men and women would improve the quality of life for everyone.

\section{Two Years of Argument and Persuasion}

In 1974 the heads of agricultural stations in Northern Ghana were invited to devote one of their monthly meetings to nutrition and health. A fruitful meeting was finally held in 1976 after two years of argument and persuasion. Some participants argued that they were not responsible for any negative side effects resulting from their activities (such as irrigation programmes leading to more malaria and bilharzia). They argued that the promotion of non-nutritious crops such as cotton and lettuce would not put nutrition at risk because men could use the cash to buy food. They did not agree that these changes made food supplies more insecure for women and children because it put the control of food availability wholly into the hands of male farmers and Cotton Board price fixers.

However, workshops and integrated training programmes were set up and the more flexible voluntary agency agriculturalists became interested in nutrition. Some discussed the district programme's monthly nutrition and health newsheet at their farmers' meetings. The integrated 'roving' extension programme was made up of teams of agricultural and nutrition extension officers. However, integration was not yet complete: the agriculturalist talked to the men about farming and the nutritionist to the women about cooking! Our interdisciplinary reading and discussions with local men and women increased our understanding of the ways in which agricultural programmes affect the lives of women and nutrition programmes affect the lives of men. This led to the establishment of the Home and Farm Extension Service of Northern Ghana which reaches men and women as farmers and parents. Guidelines put together in a training workshop in Navrongo in 1982 completely integrated information on agriculture, health and nutrition for men and women [Field guide for agricultural and health extension workers 1983].

\section{'See How They Grow' [Morley and Woodland 1979]}

The regular weighing of children and the use of a graphic growth chart is one of four activities in UNICEF's new strategy for healthy children by the year 2000. In Bawku district, as in most programmes, this information was used to motivate mothers to feed their children better. It became clear that many mothers could not do this, particularly in the farming season. However, the information was also put to another use. Bawku has unreliable rainfall and serious food shortages. The HAN (health, agriculture, nutrition) leaders used information from growth charts and rapid surveys to monitor food supplies and warn the relevant ministries of the danger of imminent famine. After several years of writing and talking about the insecurity of food supplies a nutritional surveillance system was set up over the region [Gordon 1981].

The lesson to be drawn from this is that if resources are to be spent on weighing all children, it is crucial that this information be used to alert planners and policy makers to the deprivation of certain groups, and to the nutritional implications of planned and unplanned development. If it is only fed back to mothers it will increase anxiety and divert resources from tackling the 
real causes of poor growth. We need more case studies, particularly of efforts made by professional and women's groups to influence policy, planning and local development programmes.

\section{Put Your Own House in Order}

Within the Ministry of Health, high status workers with access to and control of resources tend to be male, while women work in low status sectors, and are subordinate to men. Doctors and pharmacists in the hospitals, and male village health workers (VHW) provide costly, appreciated curative care. This leaves midwives, community health nurses and female VHWs without the resources and credibility needed for a good preventive programme; they are left with little but advice to offer women and children. Case studies and data on resource allocation would give the disadvantaged sectors ammunition with which to fight for a more equal share of resources.

Women may oppress each other in the provision of health care. Expatriate women without children demand that auxiliaries return to normal work after three months' maternity leave with the infant out of sight and mind at home. Discipline and imposed work norms prevent the auxiliary from teaching nutrition in the best way, by demonstration. Qualified health workers may have patronising or contemptuous attitudes to their unschooled rural clients. Western trained health-workers preach against traditional birth attendants and treat VHWs as 'illiterates posing as experts'. Imaginative research using discussion groups, role plays and attitude questionnaires could help raise awareness of these conflicts.

\section{Let the Problems Speak for Themselves}

In this final section I would like to summarise briefly the major priority areas for future research. For the success of such research, it should be carried out in close cooperation with local women.

\section{Water and fuel}

Research is needed into ways of meeting household needs for water and fuel more easily. This would bring many benefits by reducing the time and energy Third World women presently devote to carrying water and searching for fuel:

- improved hygiene and less disease;

- safer and more frequent meals;

- more use of legumes (which take a lot of time, and therefore fuel, to cook);

- a smaller gap between energy intakes and energy expenditure as workloads decrease;

- more time for leisure, learning, producing, and enjoying children;
- healthier women, safer pregnancies, heavier newborns.

Hoskins [1979] gives guidelines on making a community diagnosis on fuel needs with local women.

\section{Meals on the consumer's doorstep}

Research into the methods and economics of smallscale women food processors aimed at protecting and improving the industry would benefit nutrition in two ways:

- more nutritious, palatable and cheap meals would be available in the community;

- women's income would increase.

Simmons [1975] and Carr [1978] suggest ways to reduce workloads, increase profits and support women food processors.

\section{Family planning}

In the early 1970s the Bawku programme encouraged women to start oral contraception at the postpartum visit, although women abstain from sex for at least a year after delivery. Lactating women are not allowed to have sex. If women on the pill are urged to resume sex early, they will wean early, putting the child at high risk of malnutrition. If these women fail to prevent conception and are refused an abortion, the short birth interval will damage the toddler, mother and foetus. Research on local spacing methods and changing practices is needed. Then programmes can provide contraception on request at the appropriate time with acceptable technology [Bamisaiye 1978].

\section{High female mortality}

In Northern Ghana the number of girls of 10 to 14 years is only 70.6 per cent of the number of boys in this age group, apparently in large measure as a result of the practice of female excision.

Local midwives were working to stop this practice. They had suffered the pain and loss of excision themselves; seen young girls die from blood loss and women terribly torn in childbirth because of scar tissue. Whereas the excess mortality in girls is only seen in Northern Ghana where excision is practised, there may be contributory factors such as smaller shares of food and more infections in childminders. More research is needed on the causes of mortality in female children.

\section{Learning from experience}

Personal experience has taught me that many nutritional messages which seem logical in scientific isolation are absurd in practice. Open discussions and participant observation are needed to understand the 'how, when, where and why' of food allocation and consumption. 


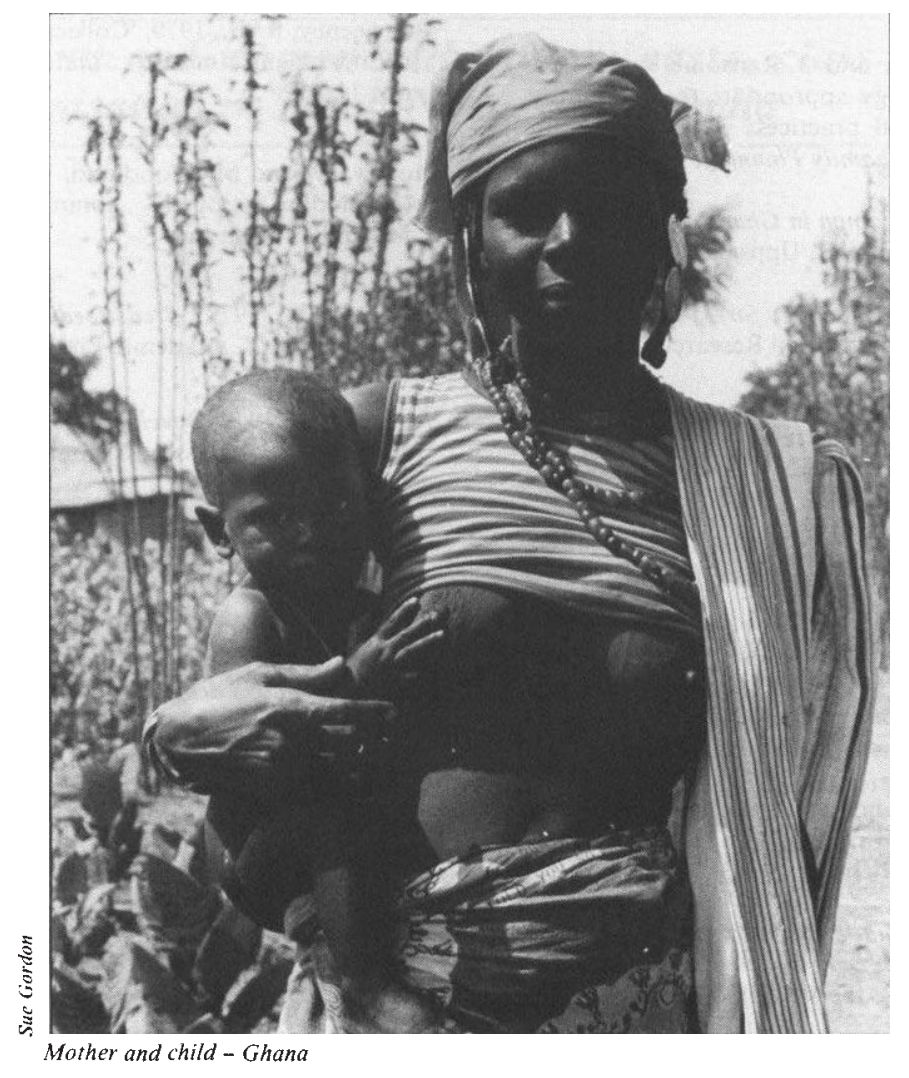

For example, in Bawku pregnant women eat little in order easily to deliver a small baby, which is sensible if you have a narrow pelvis and no local maternity service. Food is used to socialise children in the values of sharing and exchange and integrate them into their society. This is in conflict with a standard piece of nutritionist's advice: 'Give children their own bowls so that you can see how much they have eaten'. Women where I worked had many practical objections to this recommendation. 'The grass is greener on the other side, and children prefer to eat from other people's bowls'. 'You can't teach sharing if you insist that everyone sticks to their own bowl'. 'Bowls cost money, and in the hungry season amounts in each bowl would be miserably small'. My own experience is that the more we fuss over how much food our children eat, the less they will eat. We must understand the cultural, economic and social context of good practices as well as their nutritional implications.

Many nutrition educators describe weaning practices as abrupt, irrational and neglectful. (On the other hand, Zemplein-Rabain [1968] describes weaning as a gradual, rational process if it is studied over time.) As a result simplistic recommendations are offered.
'Don't abruptly deny the breast to a child, do it gradually and kindly'. However, many mothers argue that children who suck into the second year are very determined to continue forever. It is easier for the mother, and probably the child, to end the struggle quickly and avoid the fussing and clinging as the child tries to go on sucking.

It is not surprising that many mothers have no time for nutrition education. Their priorities are higher incomes, easier domestic work and less sickness. To deal with these issues nutritionists must take off their professional blinkers and tackle the real causes of malnutrition in a flexible, dynamic and interdisciplinary way.

Nutrition education has for too long been essentially a one-way process with the trained 'professionals' doing all the talking. It is time that we paid more attention to the experience, knowledge, and expressed needs of mothers, the 'target group'. Feminist nutrition research involves first and foremost listening to and learning from mothers, rather than imposing any $a$ priori scientific research agenda. 


\section{References}

Bamisaiye, E., C. de Sweemer and O. Ransome-Kuti, 1978, 'Developing a clinic strategy appropriate to community family planning needs and practices: an experience in Lagos, Nigeria', Studies in Family Planning, vol 9 nos 2/3

Bukh, J., 1977, The Village Woman in Ghana, Scandinavian Institute of Development Studies, Uppsala

Carr, M., 1978, Appropriate Technology for African Women, United Nations African Training and Research Centre for Women, Addis Ababa

Conti, A., 1979, 'Women on schemes in Upper Volta', Review of African Political Economy, nos 15/16, May-December

Draper, P. et al, 1980, 'Three types of health education', British Medical Journal, vol ii, p493

FAO Food and Nutrition Paper 8, 1979, Women in Food Production, Food Handling and Nutrition, with special emphasis on Africa; a report of the protein-calorie advisory group of the United Nations system, June 1977, FAO, Rome

'Field guide for agricultural and health extension workers', 1983, (based on the training for CAP/FHIG field assistants at IFCAT Navrongo, 7-12 February 1983), mimeo

Gordon, G. M., 1972, An Evaluation of Nutrition Education to Pregnant and Lectating Women in Six Communities in the Upper Region of Ghana, MSc thesis, University of Ghana, Legon

-1981 , 'The hungry season in the savanna of West Africa', Development Digest 5, summer, IDS, Sussex

Hoskins, M., 1979, 'Women in forestry for local community development', a programming guide, Office of women in development, Agency of International Development, Washington, DC, 20523
McSweeney, B. G., 1979, 'Collection and analysis of data on rural women's time use', Studies in Family Planning, vol 10 nos $11 / 12$

Morley, D. and M. Woodland, 1979, See How They Grow, (Macmillan tropical community health manuals), Macmillan, London

Raphael, D., 1979, Breastfeeding and Food Policy in a Hungry World, Academic Press, London

Schofield, S., 1979, Development and the Problems of Village Nutrition, IDS, Sussex, Croom Helm, London

Simmons, E. B., 1975, 'The small-scale food processing industry in northern Nigeria', Food Research Institute Studies, vol 14 no 2

Tripp, R., 1978, Economic Strategies and Nutritional Status in a Compound Farming Settlement in Northern Ghana, doctoral dissertation, Columbia University, New York

Watkinson, M., 1981, 'Delayed onset of weaning diarrhoea associated with high breast milk intake', Royal Society of Tropical Medicine and Hygiene, 75, pp432-5

Werner, D. and B. Bowes, 1982, Helping Health Workers Learn, The Hesperian Foundation, PO Box 1692, Palo Alto, California 94302, USA

Whitehead, A., 1981, 'I'm hungry, Mum' in K. Young, C. Wolkowitz and R. McCullagh (eds), Of Marriage and the Market, CSE Books, London

Zemplein-Rabain, J., 1968, 'L'aliment et la strategie de l'apprentissage avec les frères chez l'enfant Wolof', Psychopathologie Africaine, vol 4 no 2, pp297-312 